EVERYDAY SADISM, DARK TRIAD, PERSONALITY AND DISGUST SENSITIVITY: 1

EVERYDAY SADISM, THE DARK TRIAD, PERSONALITY, AND DISGUST

SENSITIVITY

Myrthe Meere, Vincent Egan*

Centre for Forensic and Family Psychology,

YANG Fujia Building,

University of Nottingham,

Wollaton Road,

Nottingham,

NG8 1BB, UK

*Corresponding author

Email: vincent.egan@nottingham.ac.uk

Running header: EVERYDAY SADISM, PERSONALITY, AND DISGUST SENSITIVITY

In Press, PAID, 2017. 
EVERYDAY SADISM, THE DARK TRIAD, PERSONALITY AND DISGUST SENSITIVITY

\begin{abstract}
Research into dark personalities has advocated for the addition of sadism due to its close relationship with other dark traits (Book et al., 2016). Lower disgust for atavistic and animalistic tendencies may provide an objective marker of the greater predatory tendencies and desire for power represented by everyday sadism. In the present study, we explored selfreported personality and disgust traits underlying non-sexual 'everyday' sadism (Buckels, Jones \& Paulhus, 2013). In line with previous research, it was predicted sadism would be negatively correlated with the honesty-humility, agreeableness and emotionality dimensions of the HEXACO, and positively correlated with psychopathy and Machiavellianism from the Dark Triad. As an added dimension, the study also investigated disgust sensitivity's relationship to sadism. A total of 235 participants (66.4\% female, $31.1 \%$ male; mean age 31.35 years $(\mathrm{SD}=13.97$ years $)$ ) completed an online survey comprising a series of psychometric measures. Results indicated that extraversion, psychopathy, Machiavellianism and animal reminder disgust were significant predictors of sadism scores. Future studies may want to include a measure of disgust sensitivity (including behavioral indices) to investigate its relationship with sadism and the DT.
\end{abstract}

Keywords: sadism, Dark Triad, Dark Tetrad, HEXACO, personality, disgust sensitivity 
EVERYDAY SADISM, DARK TRIAD, PERSONALITY AND DISGUST SENSITIVITY: 3

\section{EVERYDAY SADISM, THE DARK TRIAD, PERSONALITY AND DISGUST SENSITIVITY}

The Dark Triad' (DT: psychopathy, Machiavellianism and narcissism) assesses subclinical expressions of disagreeable personality traits. Classically, narcissists have a grandiose sense of self and crave positive attention; Machiavellians manipulate social situations; and psychopaths are callous and lack empathy (Paulhus, 2014). Males typically score higher on DT traits than females, regardless of the DT measure used (Furnham, Richards \& Paulhus, 2013). Whilst the DT dimensions are significantly correlated (Egan, Chan \& Shorter, 2014) they are sufficiently separate to merit individual examination (O’Boyle, Forsyth, Banks \& McDaniel, 2012). Self-reported DT ratings are associated with a variety of antisocial behaviours; delinquency and aggression in children (Muris, Meesters \& Timmermans, 2013); aggression in young adults (Bartlett, 2016); violence (Pailing, Boon, \& Egan, 2014); intimate partner violence (Carton \& Egan, 2017); bullying (Baughman, Dearing, Giammarco \& Vernon, 2012); counterproductive work behaviours (O’Boyle et al., 2012); and risky and sensation-seeking activities (Crysel, Crosier \& Webster, 2013).

\section{The Dark Triad and everyday sadism}

It has been suggested sadism be added to the DT, forming a Dark Tetrad (Buckels, Jones \& Paulhus, 2013; Chabrol, van Leeuwen, Rodgers \& Séjourné, 2009). Sadism is the derivation of pleasure from the distress or harm of others (Baumeister \& Campbell, 1999). Research on this topic typically concerns sexual sadism and sadism in sex offenders, as diagnosis of sadism for sex offenders can be a strong indicator for violent sexual and nonsexual reoffending (Eher et al., 2015). Sexual sadism also occurs at subclinical levels, for instance in a preference for BDSM (bondage-discipline, domination-submission, and sadomasochism), a sexual proclivity where individuals gain pleasure from their own or another's pain or enactment of such activity (Hébert \& Weaver, 2014; Richters, Visser, 
Rissel, Grulich \& Smith, 2008). However, not all sadism is sexual. In a sample of violent offenders, though psychopaths were more sadistic than non-psychopaths, violent and sexually violent psychopaths did not significantly differ in sadistic traits (Holt, Meloy \& Strack, 1999). Non-sexual, subclinical sadism has been labelled ‘everyday sadism' (Buckels et al., 2013), and reflects cruelty in everyday life, for example watching violence on TV and in films, or taking pleasure from viewing sports combat involving humans and animals (Baumeister \& Campbell, 1999). This is seen where higher levels of everyday sadism are correlated with hours spent playing violent video games (Greitemeyer, 2015). Under certain conditions, traits associated with the DT may be adaptive; psychopathic traits enable guiltfree executive decision-making by professions such as lawyers, businessmen and politicians (Mullins-Sweatt, Glover, Derefinko, Miller \& Widiger, 2010); Machiavellianism may be functional in complex social groups (Castille Buckner, \& Thoroughgood, 2016); narcissism may reduce doubts projected onto romantic partners (Foster \& Campbell, 2005); and sadism and cruelty may reflect satisfaction with achieving domination, reflecting an evolved mechanism for human predation and power struggles (Nell, 2006).

\section{Behavioural measures of Dark Tetrad}

Justifying expansion of the DT, Buckels and colleagues (2013) suggest that while DT aggression tends to be context-dependent, sadists want to aggress sufficiently to expend time and resources on the behaviour, regardless of whether there are any obvious benefits. For example, participants scoring high on Dark Tetrad traits will aggress against innocent opponents if the aggression is easy, but only sadists increase the intensity of a white-noise attack for opponents who can't fight back; in this task sadists were also willing to spend more time and energy hurting their opponents in a behavioural (but factitious) "bug-killing" paradigm, finding higher sadism scores associated with choosing to kill insects; sadistic individuals reported more post-task pleasure after having ostensibly killed insects. A study of 
violent video games found that while exposure to these kinds of games was significantly associated with Machiavellianism and psychopathy, sadism was the best predictor of their use (Greitemeyer, 2015). Lastly, the Dark Tetrad predicts Internet 'trolling' (destructive and purposeless Internet bullying); sadism, psychopathy, and Machiavellianism were significantly higher in individuals who reported trolling as their most enjoyable activity on the Internet (Buckels, Trapnell \& Paulhus, 2014).

The Dark Tetrad and personality

The general HEXACO personality model, with domains of honesty-humility, emotionality, extraversion, agreeableness, conscientiousness and openness to experience (Ashton \& Lee, 2009) outperforms other personality measures for capturing the core personalities of the Dark Tetrad (Book, Visser \& Volk, 2015). Central to the Dark Tetrad is the negative pole of the honesty-humility dimension of HEXACO (the trait's positive pole comprising sincerity, fairness, greed avoidance and modesty; Ashton, Lee \& de Vries, 2014). Honesty-humility is consistently negatively associated with Machiavellianism, narcissism and psychopathy (Lee \& Ashton, 2005), and more recently sadism (Book et al., 2016), suggesting individuals with higher Dark Tetrad scores are more likely to manipulate and take advantage of others, flaunt their wealth, and consider themselves superior to others (Ashton et al., 2014). Narcissism is significantly correlated with high levels of extraversion and low levels of agreeableness, congruent with the stereotypical view of narcissists as individuals who crave attention and have a strong need for self-enhancement (Campbell \& Campbell, 2009). While narcissists can simply be high in self-regard and not otherwise disagreeable (Egan et al., 2014), Machiavellianism and psychopathy are unambiguously associated with low agreeableness, consistent with their shared manipulative and self-serving nature (Paulhus et al., 2013). Psychopathy also has elements of low conscientiousness and low emotionality, underpinning the more specifically callous and irresponsible nature of the trait. Finally, low 
emotionality and low agreeableness are key predictors of sadism, hence sadistic indifference or pleasure at the suffering or pain of others (Baumeister \& Campbell, 1999). Similar results are seen in those with sadistic personality disorder (Hagger-Johnson \& Egan, 2010).

\section{Disgust sensitivity}

Disgust is an evolutionary mechanism that originated as a response to potential contamination and putrefaction, enabling the rejection of foods that might otherwise expose one to illness (Rozin, Haidt \& McCauley, 1999). It has been argued that the disgust system adapted to inform human mate choice and social morality (Tybur, Lieberman, Kurzban, \& DeScioli, 2013). Research concerning disgust sensitivity focuses on three main areas: core disgust, animal reminder disgust, and contamination based disgust (Olantunji, Haidt, McKay \& David, 2008). Core disgust reflects the perceived threat of disease through aversive stimuli such as rotting food and vermin (Rozin, Haidt \& McCauley, 2000). Animal reminder disgust results from an aversion to reminders of our animal origin such as our mortality (Olantunji et al., 2008). Finally, contamination-based disgust emphasizes disgust arising from potential threat of infection, such as using a public bathroom (Olantunji et al., 2008). Disgust sensitivity alters personality traits: as a way of avoiding infectious individuals, individuals primed to become worried about diseases rate themselves as less agreeable, less extraverted and less open to experience (Mortensen, Becker, Ackerman, Neuberg \& Kenrick, 2010).

Previous studies have investigated the relationship between disgust sensitivity and moral hyper-vigilance. Offences of an immoral nature such as child sexual abuse (as well as such offenders) elicit visceral disgust in some individuals (Jones \& Fitness, 2008). Individuals who find another person "disgusting" seek to distance themselves from these individuals and offences. In this context, disgust functions as an emotional response that makes an individual feel superior to others who they view with repulsion and disapproval. Disgust sensitivity also has implications on aggressive behaviour: individuals with higher 
disgust sensitivity are less physically and verbally aggressive (Pond, DeWall, Lambert, Deckman, Bonser \& Fincham, 2012). In essence, disgust is a 'defensive' behaviour, and disgust-display avoidance may denote important aspects of character (Richman, DeWall, Pond, Lambert \& Fincham, 2014; Pond et al., 2012). Moral hyper-vigilance may occur in individuals sensitive to, or disgusted by offenses of a moral nature, who, in turn, are less willing to hurt, and emotionally distance themselves from antagonistic others (Pond et al., 2012). To date, there has only been one study of sadism that has included a measure of disgust sensitivity; Buckels et al (2013), who found sadism unrelated to disgust sensitivity in undergraduates. The relationship between sadism and disgust sensitivity has not been specifically explored in a more general sample, and therefore warrants further investigation.

\section{The present study}

In the present study, we sought to replicate and extend the previous study of personality correlates of non-sexual sadism, seeking to identify the highly correlated predictors of this construct. Based on previous research, we predicted that sadism would have a significant positive relationship with psychopathy and Machiavellianism, but, because of its mixed profile, narcissism's influence on these constructs would be reduced (Hypothesis 1; Greitemeyer, 2015; Buckels et al, 2014). Additionally, in line with previous research, it was predicted that sadism scores would be negatively associated with the honesty-humility, agreeableness and emotionality dimensions of the HEXACO (Hypothesis 2; Book et al., 2016; Baumeister \& Campbell, 1999). As an additional predictor, disgust sensitivity was used to shed more light on its possible relationship with sadism in the context of moralhypervigilance (Hypothesis 3; Richman, DeWall, Pond, Lambert \& Fincham, 2014; Pond et al., 2012).

\section{METHOD}




\section{Participants:}

G-Power suggested that for a power of 0.15 , an error rate of 0.05 , and a power of 0.95, a minimum sample size of 186 would be necessary (Faul, Erdfelder, Buchner., \& Lang, 2009). A sample of 236 participants $(\mathrm{F}: \mathrm{M}=156: 73$, mean age $=31.35$ years $(\mathrm{SD}=13.97$ years)) completed the survey. The study had ethical approval by the Faculty of Medicine \& Health Sciences (FMHS) Research Ethics Committee.

Procedure:

All participants were over the age of 18 and recruited via social media sites, such as Facebook and Reddit.com, as well as participant recruitment sites (callforparticipants.com, and Hanover online research). Participants completed the questionnaire through the Bristol Online Survey website (https://www.onlinesurveys.ac.uk). Participants filled out a consent form prior to taking part in the study. The study was quantitative and cross-sectional in nature, and the key outcome was self-reported sadism.

\section{Measures:}

HEXACO-60 (Ashton \& Lee, 2009)

The HEXACO-60 comprises 60 items used to measure personality on six dimensions: honesty-humility, emotionality, extraversion, agreeableness, conscientiousness, and openness to experience. Each subscale consists of 10 items, rated on a 5-point Likert scale indicating how much individuals agreed with the statement, where ' 1 ' is strongly disagree and ' 5 ' is strongly agree. Community and college samples indicate reliabilities for the HEXACO-60 subscales to be in the 0.70 s (Ashton \& Lee, 2009).

The Short DT (SD3; Jones \& Paulhus, 2014)

The SD3 consists of 27 items measuring Machiavellianism, narcissism and psychopathy. Each subscale comprises of 9 items, rated on a 5-point Likert scale where ' 1 ' is 
strongly disagree and ' 5 ' is strongly agree. The SD3 scales are reliable: Machiavellianism $\alpha$ $=0.75$, psychopathy $\alpha=0.72$ and narcissism $\alpha=0.73$ (Jones \& Paulhus, 2014).

Short Sadistic Impulse Scale (SSIS; O'Meara, Davies \& Hammond, 2011)

The SSIS measures non-sexual sadism and consists of 10 items, rated on a 4-point Likert scale (' 1 ' is strongly agree to ' 4 ' is strongly disagree (sample item: "I have hurt people for my own enjoyment")). Lower scores indicate greater sadism. The SSIS is a reliable measure of sadistic impulses, and has an internal consistency of 0.86 (O'Meara et al., 2011). Disgust Scale - Revised (DS-R; Olatunji et al., 2007)

The DS-R has 25 items split into two sections, and measures individuals on three dimensions of disgust: core disgust (sample item: "It would bother me to see a rat run across my path in a park"), animal reminder disgust (sample item: "It would bother me to be in a science class, and see a human hand preserved in a jar"), and contamination-based disgust (sample item: "Your friend's pet cat dies and you have to pick up the dead body with your bare hands"). In part 1, participants were asked to respond to statements with 'True' or 'False'. In part 2, participants were asked to rate these statements as "not", "slightly", or "very" disgusting. The DS-R has an overall internal consistency of 0.84 ; the reliabilities for the subscales are: core disgust $\alpha=.74$, animal reminder disgust $\alpha=.78$ and contaminationbased disgust $\alpha=.61$ (Olatunji et al., 2007).

\section{RESULTS}

Insert table 1 here 
Data were exported into SPSS and tests for normality conducted. Sadism is uncommon in the population, and preliminary analysis indicated skewed sadism scores $($ skewness $=1.740$, kurtosis $=3.538)$. These data were root-transformed so parametric tests could be completed; how we managed heteroscedasticity is discussed in the regression section below. Reliabilities, means and standard deviations for all scales are provided in Table 1. The contamination-based disgust subscale of the DS-R was not reliable, so was not used for further analyses. Reliability of the SSIS was initially lower than expected. Inspection of the items found removal of reverse-keyed question 8 of the SSIS ("I wouldn't intentionally hurt anyone") greatly improved reliability. Reverse-phrasing of the question may have confused participants. The final SSIS consisted of nine questions (alpha $=0.89$ ).

Insert table 2 and 3 here

\section{Correlations between measures.}

Correlations between the HEXACO and the SD3, SSIS, and measures of disgust were in the predicted directions (table 2). Honesty-humility was significantly associated with all three SD3 dimensions plus sadism. Narcissism was significantly associated with extraversion. Animal reminder disgust was greater in persons who were higher in emotionality. The mean $r$ between the DT subscales was 0.54 ( $p<.001)$. Associations between the dark tetrad of psychopathy, Machiavellianism, narcissism, and root SSIS sadism scores with core disgust and animal reminder disgust were mostly significant, in the predicted negative direction, and higher in magnitude for sadism (table 3).

Insert table 4 here 


\section{Multiple linear regression}

Due to substantial levels of correlation in the data set, it was necessary to untangle the covariance to establish the significant sources of predictable variance on everyday sadism. A further complication was, because of sadism's inherent non-normality, the sadism variable was skewed. Root-transformation improved, but did not resolve heteroscedasticity (variable error variance across the distribution), which remained significant (Koenker test $\chi^{2}=35.17$; http://www.spsstools.net/Syntax/RegressionRepeatedMeasure/BreuschPaganAndKoenkerTest.txt ). To overcome this difficulty, a multiple regression was calculated using heteroscedasticity-consistent standard error estimators (Hayes \& Cai, 2007; macro for SPSS from http://afhayes.com/spss-sas-and-mplus-macros-and-code.html). To identify which variables were significant predictors of sadism, a multiple regression was performed with the following variables; demographics (age and gender), the six HEXACO personality dimensions, the three DT dimensions, and core and animal reminder disgust. The logic of this model was that we sought to find the sources of variance in everyday sadism, so proceeded from generic demographics, to standard personality variance, then the DT, and finally the new construct - disgust, moving from the most general to the highly specific.

Table 4 contains the standardized betas $(\beta), t$-values, $R^{2}$, and significance of the final model in the multiple regression. The model was highly significant $(F(13,217)=12.12 p<.001)$ and accounted for $45 \%$ of the variance in sadism scores. Lower extraversion, lower animal reminder disgust, and higher Machiavellianism and psychopathy were all significant predictors of sadism.

\section{DISCUSSION}

We found that lower extraversion and animal reminder disgust, and higher Machiavellianism and psychopathy scores predicted greater everyday sadism. We reiterate 
the significant positive relationship between psychopathy, Machiavellianism, and sadism. It has been repeatedly observed in studies of the DT / Dark Tetrad and personality that extraversion is positively and significantly associated with narcissism, and agreeableness negatively associated with all three DT constructs (Book et al., 2016).

Our findings did not find narcissism - at least in the form measured by the SD3 - a strong contributory predictor of negative outcomes other than lower honesty-humility (see Greitemeyer, 2015; Buckels et al, 2014). Narcissism is complex (Egan et al, 2014) and a less 'dark' trait than psychopathy or Machiavellianism; some narcissistic qualities (e.g., boldness, leadership) are positive virtues (Rauthmann \& Kolar, 2012). It nevertheless remains the case that narcissism coheres with the Dark Triad to a degree, and here almost made significance in the multiple regression predicting sadism. This is because both subclinical psychopathy and facets of narcissism stem from clinical expressions of personality, hence their loading on the same factor (albeit sometimes with a split loading for narcissism due to other facets of the narcissism construct; Egan et al, 2014). Machiavellianism, psychopathy, and narcissism all fall under the quadrant of high agency and low communion, leading to a core of manipulation and callousness that may have been expedient for survival during much of our evolution (e.g., Furnham et al, 2013; Jones \& Paulhus, 2014; Jones \& Figueredo, 2013).

\section{Disgust and sadism}

A novel development of this study was its use of disgust sensitivity as a marker of sadism. While only core and animal reminder disgust DS-R subscales were reliable, this construct was also significantly associated with sadism. Disgust reminds humans of their base origins; Rozin and colleagues (1999) suggest we do not generally like to be reminded of our corporality, and disgust enables such thoughts to be rejected. For example, persons high on the animal reminder measure shown a video of open-heart surgery are significantly more likely to avoid looking at the video (Olatunji et al., 2008); individuals with higher animal 
reminder disgust watching a video of blood being drawn show more facial muscle tension and lower heart rates (Olantunji et al., 2008). These scenarios illustrate the moral hypervigilance theory of disgust (Jones \& Fitness, 2008). Although Buckels et al's (2013) faux-bug-killing paradigm suggested sadism was not related to disgust sensitivity, their study had a significantly smaller sample size $(n=78)$, and involved a student cohort with a mean age of 20.37 years; students are a particularly WEIRD (Western, Educated, Industrialized, Rich, and Democratic) population (Henrich, Heine, \& Norenzayan, 2010). It is possible that the current study is more representative of the general population, and may more accurately reflect sadist's lower disgust sensitivity. Given the effectiveness of sensory and physical cues to evoke behavioural disgust, such stimuli could be readily used in experimental studies of mechanisms underlying sadism, just as gustatory taste has also been examined in relation to the Dark Tetrad (Sagioglou \& Greitemeyer, 2016).

\section{Limitations and future directions}

A limitation of the current study is its reliance on self-report data and limited sampling of everyday sadistic behaviours. Experimental stimuli involving grotesque pictures or unusual flavours and tastes, and sensitivity to the products of bodily excretion are established paradigms in psychology, and suggest new ways of researching non-sexual sadism. Such an approach overcomes difficulties with ethics due to the facilitation of aggressive and malevolent behaviour (Paulhus, 2014), and complements research on, for example, Internet trolling (Buckels et al., 2014). This study replicates personality and DT correlates of non-sexual sadism, and suggests that disgust sensitivity may provide a potentially straightforward and objective means of conducting experiments in this area. 


\section{REFERENCES}

Ashton, M.C. \& Lee, K. (2009). The HEXACO-60: A short measure of the major dimensions of personality. Journal of Personality Assessment, 91(4), 340-345. doi: $10.1080 / 00223890902935878$

Ashton, M. C., Lee, K. \& de Vries, R. E. (2014). The HEXACO Honesty-Humility, Agreeableness, and Emotionality factors: A review of research and theory. Personality and Social Psychology Review, 18(2), 139-152. doi: $10.1177 / 1088868314523838$

Baumeister, R. F. \& Campbell, W. K. (1999). The intrinsic appeal of evil: Sadism, sensational thrills, and threatened egotism. Personality and Social Psychology Review, 3(3), 210-221. doi: 10.1207/s15327957pspr0303_4

Baughman, H. M., Dearing, S., Giammarco, E. \& Vernon, P. A. (2012). Relationships between bullying behaviours and the Dark Triad: A study with adults. Personality and Individual Differences, 52(5), 571-575. doi: 10.1016/j.paid.2011.11.020

Book, A., Visser, B. A., Blais, J., Hosker-Field, A., Methot-Jones, T., Gauthier, N. Y., Volk, A., Holden, R.R. \& D'Agata, M. T. (2016). Unpacking more "evil": What is at the core of the dark tetrad?. Personality and Individual Differences, 90, 269-272. doi: 10.1016/j.paid.2015.11.009

Book, A., Visser, B. A. \& Volk, A. (2015). Unpacking "evil": Claiming the core of the Dark Triad. Personality and Individual Differences, 73, 29-38. doi: 10.1016/j.paid.2014.09.016

Buckels, E. E., Jones, D. \& Paulhus, D. L. (2013). Behavioral confirmation of everyday sadism. Psychological Science, 24(11), 2201-2209. doi: 10.1177/0956797613490749 
Buckels, E. E., Trapnell, P. D. \& Paulhus, D. L. (2014). Trolls just want to have fun. Personality and Individual Differences, 67, 97-102. doi: 10.1016/j.paid.2014.01.016

Campbell, W.K. \& Campbell S.M. (2009). On the self-regulatory dynamics created by the peculiar benefits and costs of narcissism: A contextual reinforcement model and examination of leadership. Self and Identity, 8(3), 214-232. doi:

$10.1080 / 15298860802505129$

Carton, H. \& Egan, V. (2017). The dark triad, psychological abuse, and intimate partner violence. Personality and Individual Differences, 105, 84-88. doi: 10.1016/j.paid.2016.09.040

Castille, C. M., Buckner, J. E. \& Thoroughgood, C. N. (2016). Prosocial citizens without a moral compass? Examining the relationship between Machiavellianism and unethical pro-organizational behavior. Journal of Business Ethics, 140(1), 1-12. doi: 10.1007/s10551-016-3079-9 (in press).

Chabrol, H., Van Leeuwen, N., Rodgers, R. \& Séjourné, N. (2009). Contributions of psychopathic, narcissistic, Machiavellian, and sadistic personality traits to juvenile delinquency. Personality and Individual Differences, 47(7), 734-739.

Crysel, L. C., Crosier, B. S. \& Webster, G. D. (2013). The Dark Triad and risk behavior. Personality and Individual Differences, 54, 35-40. doi:10.1016/j.paid.2012.07.029

Egan, V., Chan, S. \& Shorter, G.W. (2014).The dark triad, happiness, and subjective wellbeing. Personality and Individual Differences, 67, 17-22. doi: 10.1016/j.paid.2014.01.004

Eher, R., Schilling, F., Hansmann, B., Pumberger, T., Nitschke, J., Habermeyer, E. \& Mokros, A. (2015). Sadism and violent reoffending in sexual offenders. Sexual 
EVERYDAY SADISM, DARK TRIAD, PERSONALITY AND DISGUST SENSITIVITY: 16

Abuse: A Journal of Research and Treatment, 28, 46-72.

doi:10.1177/1079063214566715

Faul, F., Erdfelder, E., Buchner, A. \& Lang, A. G. (2009). Statistical power analyses using G*Power 3.1: Tests for correlation and regression analyses. Behavior Research Methods, 41(4), 1149-1160. doi:10.3758/BRM.41.4.1149

Foster, J. D. \& Campbell, W. K. (2005). Narcissism and resistance to doubts about romantic partners. Journal of Research in Personality, 39(5), 550-557. doi: 10.1016/j.jrp.2004.11.001

Furnham, A., Richards, S. C. \& Paulhus, D. L. (2013). The Dark Triad of personality: A 10 year review. Social and Personality Psychology Compass, 7(3), 199-216. doi: $10.1111 / \mathrm{spc} 3.12018$

Greitemeyer, T. (2015). Everyday sadism predicts violent video game preferences. Personality and Individual Differences, 75, 19-23. doi:10.1016/j.paid.2014.10.049

Hagger-Johnson, G. \& Egan, V. (2011). Sadistic personality disorder and sensational interests: what is the size and specificity of the association? Journal of Forensic Psychiatry \& Psychology, 21, 113-120. doi: 10.1080/14789940903174220

Hayes, A. F. \& Cai, L. (2007). Using heteroscedasticity-consistent standard error estimators in OLS regression: An introduction and software implementation. Behavior Research Methods, 39(4), 709-722. doi:10.3758/BF03192961

Hébert, A. \& Weaver, A. (2014). An examination of personality characteristics associated with BDSM orientations. Canadian Journal of Human Sexuality, 23(2), 106-115. doi: $10.3138 /$ cjhs. 2467 
Henrich, J., Heine, S.J. \& Norenzayan, A. (2010). The weirdest people in the world? Behavioral and Brain Sciences, 33(2-3), 61-83. doi: 10.1017/S0140525X0999152X

Holt, S. E., Meloy, J. R. \& Strack, S. (1999). Sadism and psychopathy in violent and sexually violent offenders. Journal of the American Academy of Psychiatry and the Law, 27, $23-32$.

Jones, A. \& Fitness, J. (2008). Moral hypervigilance: The influence of disgust sensitivity in the moral domain. Emotion, 8(5), 613-627. doi:10.1037/a0013435

Jones, D. N. \& Figueredo, A. J. (2013). The core of darkness: Uncovering the heart of the Dark Triad. European Journal of Personality, 27(6), 521-531. doi: 10.1002/per.1893.

Jones, D. N. \& Paulhus, D. L. (2014). Introducing the Short Dark Triad (SD3) A Brief Measure of Dark Personality Traits. Assessment, 21(1), 28-41. doi: $10.1177 / 1073191113514105$

Lee, K. \& Ashton, M. C. (2005). Psychopathy, Machiavellianism, and Narcissism in the Five-Factor Model and the HEXACO model of personality structure. Personality and Individual Differences, 38(7), 1571-1582. doi:10.1016/j.paid.2004.09.016

Mortensen, C. R., Becker, D. V., Ackerman, J. M., Neuberg, S. L. \& Kenrick, D. T. (2010). Infection breeds reticence: The effects of disease salience on self-perceptions of personality and behavioral avoidance tendencies. Psychological Science, 21(3), 440447. doi:10.1177/0956797610361706

Mullins-Sweatt, S. N., Glover, N. G., Derefinko, K. J., Miller, J. D. \& Widiger, T. A. (2010). The search for the successful psychopath. Journal of Research in Personality, 44(4), 554-558. doi:10.1016/j.jrp.2010.05.010

Muris, P., Meesters, C. \& Timmermans, A (2013). Some youths have a gloomy side: 
EVERYDAY SADISM, DARK TRIAD, PERSONALITY AND DISGUST SENSITIVITY: 18

Correlates of the Dark Triad personality traits in non-clinical adolescents. Child

Psychiatry \& Human Development, 44, 658-665. doi:10.1007/s10578-013-0359-9

Nell, V. (2006). Cruelty's rewards: The gratifications of perpetrators and spectators.

Behavioral and Brain Sciences, 29(3), 211-257. doi:10.1017/S0140525X06009058

O'Boyle Jr, E. H., Forsyth, D. R., Banks, G. C. \& McDaniel, M. A. (2012). A meta-analysis of the dark triad and work behavior: A social exchange perspective. Journal of Applied Psychology, 97(3), 557-579. doi: 10.1037/a0025679

Olatunji, B. O., Haidt, J., McKay, D. \& David, B. (2008). Core, animal reminder, and contamination disgust: Three kinds of disgust with distinct personality, behavioral, physiological, and clinical correlates. Journal of Research in Personality, 42(5), 1243-1259. doi: 10.1016/j.jrp.2008.03.009

Olatunji, B. O., Williams, N. L., Tolin, D. F., Abramowitz, J. S., Sawchuk, C. N., Lohr, J. M. \& Elwood, L. S. (2007). The Disgust Scale: item analysis, factor structure, and suggestions for refinement. Psychological Assessment, 19(3), 281-297. doi: $10.1037 / 10403590.19 .3 .281$

O'Meara, A., Davies, J. \& Hammond, S. (2011). The psychometric properties and utility of the Short Sadistic Impulse Scale (SSIS). Psychological Assessment, 23(2), 523-531. doi: $10.1037 / \mathrm{a} 0022400$.

Pailing, A., Boon, J. \& Egan, V. (2014). Personality, the dark triad and violent behaviour. Personality and Individual Differences, 67(9), 81-86. doi: 10.1016/j.paid.2013.11.018.

Paulhus, D. L. (2014). Toward a taxonomy of dark personalities. Current Directions in Psychological Science, 23(6), 421-426. doi: 10.1177/0963721414547737 
Pond, R.S., DeWall, C.N., Lambert, N.M., Deckman, T., Bonser, I.M. \& Fincham, F.D. (2012). Repulsed by violence: Disgust sensitivity buffers trait, behavioral, and daily aggression. Journal of Personality and Social Psychology, 102, 175-188. doi: $10.1037 / \mathrm{a} 0024296$

Rauthmann, J. F. \& Kolar, G. P. (2012). How “dark" are the Dark Triad traits? Examining the perceived darkness of narcissism, Machiavellianism, and psychopathy. Personality and Individual Differences, 53(7), 884-889. doi: 10.1016/j.paid.2012.06.020

Richman, S. B., DeWall, C. N., Pond, R. S., Lambert, N. M. \& Fincham, F. D. (2014). Disgusted by vengeance: Disgust sensitivity predicts lower vengeance. Journal of Social and Clinical Psychology, 33(9), 831-846. doi:10.1521/jscp.2014.33.9.831

Richters, J., Visser, R. O., Rissel, C. E., Grulich, A. E. \& Smith, A. M. (2008). Demographic and psychosocial features of participants in Bondage and Discipline, "Sadomasochism" or Dominance and Submission (BDSM): Data from a national survey. Journal of Sexual Medicine, 5(7), 1660-1668. doi:10.1111/j.17436109.2008.00795.x

Rozin, P., Haidt, J. \& McCauley, C. R. (1999). Disgust: The body and soul emotion. In T. Dalgleish \& M. J. Power (Eds.), Handbook of cognition and emotion (pp. 429-445). West Sussex, England: John Wiley \& Sons.

Rozin, P., Haidt, J. \& McCauley, C. R. (2000). Disgust. In M. Lewis \& J. Haviland (Eds.), Handbook of emotions (2nd ed., pp. 637 653). New York: Guilford Press.

Sagioglou, C. \& Greitemeyer, T. (2016). Individual differences in bitter taste preferences are associated with antisocial personality traits. Appetite, 96(1), 299-308. doi:10.1016/j.appet.2015.09.031 
EVERYDAY SADISM, DARK TRIAD, PERSONALITY AND DISGUST SENSITIVITY: 20

Tybur, J.M., Lieberman, D., Kurzban, R. \& DeScioli, P. (2013). Disgust: Evolved function and structure. Psychological Review, 120(1), 65-84. doi: 10.1037/a0030778 
Table 1: Means, SDs and reliabilities for measured variables.

Mean SD $\alpha$

\section{HEXACO}

Honesty-Humility

Emotionality

Extraversion

Agreeableness

Conscientiousness

Openness to experience

SD3

Machiavellianism

Narcissism

Psychopathy

DS-R

Core disgust

Animal reminder disgust

Contamination-based disgust

Short Sadistic Impulse Scale (SSIS)

$\begin{array}{lll}34.29 & 7.57 \quad 0.82\end{array}$

$\begin{array}{lll}32.12 & 7.36 & 0.82\end{array}$

$\begin{array}{lll}32.10 & 7.88 \quad 0.86\end{array}$

$\begin{array}{lll}31.44 & 6.23 \quad 0.76\end{array}$

$\begin{array}{lll}35.38 & 6.21 \quad 0.78\end{array}$

$\begin{array}{lll}36.36 & 6.58 & 0.78\end{array}$

$\begin{array}{lll}27.07 & 6.86 & 0.85\end{array}$

$\begin{array}{lll}23.52 & 6.33 & 0.80\end{array}$

$\begin{array}{lll}19.43 & 5.82 & 0.75\end{array}$

$\begin{array}{lll}10.27 & 3.54 & 0.74\end{array}$

$\begin{array}{lll}5.39 & 2.82 & 0.74\end{array}$

$\begin{array}{lll}1.70 & 5.39 & 0.54\end{array}$

$\begin{array}{lll}13.04 & 4.87 & 0.89\end{array}$ 
Table 2: Correlations (Pearson's $r$ ) between the dark triad, sadism, disgust and HEXACO measures of personality $(n=235)$.

HonestyHumility

Emotionality Extroversion Agreeableness Conscientiousness Openness

$\begin{array}{lllllll}\text { Machiavellianism } & -0.64^{* *} & -0.35^{*} & 0.07 & -0.32^{* *} & -0.12 & -0.06 \\ \text { Narcissism } & -0.46^{*} & -0.32^{*} & 0.59^{* *} & -0.16^{*} & -0.02 & 0.10 \\ \text { Psychopathy } & -0.62^{*} & -0.29^{*} & 0.12 & -0.39^{* *} & -0.32^{* *} & -0.01 \\ \text { Root sadism } & -0.46^{* *} & -0.12 & -0.19^{* *} & -0.30^{*} & -0.31^{* *} & 0.02 \\ \text { Core disgust } & -0.06 & 0.36^{* *} & -0.08 & -0.09 & 0.06 & -0.17 * \\ \text { Animal reminder } & 0.10 & 0.39^{* *} & -0.02 & 0.14 & 0.05 & -0.18\end{array}$

Table legend: $*=p<.01 ; * *=p<.001$ 
Table 3: Correlations (Pearson's r) between disgust and Dark tetrad constructs $(n=235)$.

Psychopathy Machiavellianism Narcissism Root sadism

$\begin{array}{lllll}\text { Core disgust } & -0.14 * & -0.12 & -0.16 * & -0.21 * * *\end{array}$

Animal reminder disgust $-0.19 * * \quad-0.21 * * * \quad-0.12 \quad-0.29 * * *$

Table legend: $*=p<0.05 ; * *=p<.01 ; * * *=p<.001$. 
Table 4: Multiple regression predicting everyday sadism (root SSIS) from demographics, personality, DT, and disgust measures $\left(R^{2}=0.49\right.$ (adjusted $\left.R^{2}=0.45\right)$ ); heteroscedascitycorrected.

$\begin{array}{lccc} & \text { Beta weight } & t & p< \\ \text { Age } & 0.01 & -0.07 & 0.69 \\ \text { Gender } & -0.01 & -1.52 & .0 .14 \\ \text { Honesty-humility } & -0.01 & -0.48 & 0.57 \\ \text { Emotionality } & -0.03 & 1.59 & -0.09 \\ \text { Extraversion } & -0.07 & -4.12 & .001 \\ \text { Agreeableness } & -0.01 & -0.54 & 0.59 \\ \text { Conscientiousness } & -0.02 & -0.82 & 0.41 \\ \text { Openness to experience } & 0.00 & 0.07 & 0.94 \\ \text { Machiavellianism } & 0.05 & 2.41 & 0.02 \\ \text { Narcissism } & 0.04 & 1.76 & 0.08 \\ \text { Psychopathy } & -0.10 & -3.89 & 0.001 \\ \text { Core disgust } & -0.01 & -1.32 & 0.19 \\ \text { Animal reminder disgust } & -.0 .01 & -2.68 & 0.008\end{array}$

